\title{
In vitro experimental study of the relationship between the apparent diffusion coefficient and changes in cellularity and cell morphology
}

\author{
YOSHITSUGU MATSUMOTO ${ }^{1}$, MASAHIRO KURODA ${ }^{1}$, RYOHEI MATSUYA ${ }^{1}$, HIROKAZU KATO ${ }^{1}$, \\ KOICHI SHIBUYA ${ }^{1}$, MASATAKA OITA ${ }^{1}$, ATSUSHI KAWABE ${ }^{1}$, HIDENOBU MATSUZAKI ${ }^{2}$, \\ JUNICHI ASAUMI ${ }^{2}$, JUN MURAKAMI ${ }^{2}$, KAZUNORI KATASHIMA ${ }^{2}$, MASAKAZU ASHIDA ${ }^{2}$, \\ TAKANORI SASAKI ${ }^{3}$, TETSURO SEI ${ }^{3}$, SUSUMU KANAZAWA ${ }^{3}$, SEIICHI MIMURA ${ }^{4}$, \\ SEIICHIRO OONO ${ }^{4}$, TAKUICHI KITAYAMA ${ }^{4}$, SEIJI TAHARA ${ }^{4}$ and KEIJI INAMURA ${ }^{4}$ \\ ${ }^{1}$ Faculty of Health Sciences, Graduate School of Health Sciences, ${ }^{2}$ Oral and Maxillofacial Radiology and \\ ${ }^{3}$ Department of Radiology, Graduate School of Medicine, Dentistry and Pharmaceutical Sciences; ${ }^{4}$ Central Division \\ of Radiology, Okayama University Hospital, Okayama University, 2-5-1 Shikata-cho, Okayama 700-8558, Japan
}

Received April 2, 2009; Accepted May 29, 2009

DOI: 10.3892/or_00000484

\begin{abstract}
Diffusion-weighted magnetic resonance imaging (MRI) is frequently used clinically, and is available for the whole-body screening for tumors. The exact mechanism by which the apparent diffusion coefficient (ADC) value decreases in tumorous tissue remains unclear, although various theories have been proposed, including intracellular and extracellular factor theories. It is impossible to distinguish each factor in the intracellular and extracellular spaces as the source of MR signal generation by means of conventional comparison between MR images and pathological specimens. Other factors which have been reported to affect ADC include cellularity and cellular edema of human tissues, and temperature of phantoms at the time of measurement. We employed a new technique that enables cellular MR imaging using a newly developed bio-phantom containing a living culture tumor cell line, Jurkat-N1. We investigated possible reasons for observed decreases in ADC values for tumors, and we considered the contribution of both the intracellular and extracellular space to such a decrease. The ADC values of the bio-phantom increased with increasing heat exposure from 27 to $45^{\circ} \mathrm{C}$. ADC values also increased after the destruction by sonication of tumor cell membranes. ADC values decreased as cellularity increased in the bio-phantom. ADC values decreased due to cellular edema caused by a low
\end{abstract}

Correspondence to: Dr Masahiro Kuroda, Faculty of Health Sciences, Graduate School of Health Sciences, Okayama University, 2-5-1 Shikata-cho, Okayama 700-8558, Japan

E-mail: kurodamd@cc.okayama-u.ac.jp

Key words: MRI, phantom, ADC value, diffusion-weighted image, intracellular space, extracellular space salt concentration in the bio-phantom. Changes in pressure in the bio-phantom had no effect on the observed ADC values. We calculated both the intracellular ADC and extracellular ADC values using the ADC values, cellularity, and cellular volume of Jurkat-N1 cells in the bio-phantom. The extracellular ADC values in the bio-phantom were estimated to be lower than the ADC value of distilled water. These results indicate that not only intracellular ADC values, but also extracellular ADC values contribute to the determination of the ADC values of bio-phantoms. This is the first report to have examined the contribution of intracellular and extracellular space on the ADC values of bio-phantoms containing cultured tumor cells.

\section{Introduction}

Diffusion-weighted imaging (DWI) is a useful method for the early diagnosis of cerebrovascular diseases by magnetic resonance imaging (MRI). DWI has also frequently been used for whole-body screening for tumors (1). It is well known that apparent diffusion coefficient (ADC) values decrease in tumorous tissue. The ADC map that is calculated from DWI reflects the diffusion of water molecules. ADC maps are currently used for the early diagnosis and follow-up treatment of tumors (2-4), and to evaluate the degree of tumor differentiation $(5,6)$ and assess the grade of tumor malignancy (5). Recently, new pulse sequences have been developed, including diffusion-weighted whole-body imaging with background body signal suppression (DWIBS) (7).

Although the exact mechanism by which ADC values are reduced in tumors remains unclear, a number theories have been proposed to account for this phenomenon, e.g., changes in water diffusion in the intracellular space (8-10) and extracellular space (11), and those in both the intracellular and extracellular spaces (11) of tumors. In addition, changes in tumor cellularity $(6,12)$, as well as cellular necrosis and edema (11) have been suggested to be causally related to decreases 
in tumor ADC values. Thus far, these putative mechanisms of decrease have been investigated by comparison of MR images and pathological specimens obtained from patients as well as laboratory animals. However, such comparisons have not yet reliably identified a factor in either the intracellular or the extracellular space as the source of signal generation during MR imaging. The factors affecting the diffusion of water molecules in general, i.e., temperature (10) at the time of measurement, have been reported as exerting an effect on signal generation.

Here we developed a new technique that enables cellular MR imaging using a newly developed bio-phantom which could contain living-culture tumor cells. This system was developed in order to separately investigate the involvement of intracellular and extracellular factors. MR imaging of living-culture tumor cells enables the experimental creation and imitation of various clinical conditions caused by tumors; thus, the relationship between MR imaging and various clinical conditions such as cellularity, cellular edema, temperature, and pressure can be effectively and reliably observed in a bio-phantom.

No studies reported to date have provided the precise ADC values of the intracellular and extracellular space in tumorous tissue. This is the first report of a study in which the contribution of the intracellular and extracellular space to ADC values was examined using bio-phantoms containing cultured tumor cells.

\section{Materials and methods}

Preparation of bio-phantom containing cultured tumor cells Cells and cell culture. We used Jurkat-N1 cells for the present study. The Jurkat-N1 cell line is a stably expressing transfectant of enhanced green fluorescent protein (EGFP) established by the transfection of the pEGFP-N1 vector (Clontech Laboratories, Inc., Palo Alto, CA, USA) into Jurkat cells, a human leukemic T cell line. The cells for the present study were obtained from the RIKEN Cell Bank (Ibaraki, Japan). The cells were cultured in RPMI-1640 medium ( $\mathrm{pH} 7.4$; Gibco, Grand Island, NY, USA), and were supplemented with $10 \%$ fetal bovine serum (Filtron PTY, Ltd., Brooklyn, VIC, Australia) and 1\% penicillin-streptomycin-neomycin (Gibco). Cell culturing was performed in an incubator with 5\% $\mathrm{CO}_{2}$ plus $95 \%$ air at $37^{\circ} \mathrm{C}$.

\section{Cell treatment before encapsulation into the bio-phantom} Alteration of cellularity using the gellan gum. Cells were initially spun down into a pellet at $1200 \mathrm{rpm}$ for $5 \mathrm{~min}$. To alter cellularity in the phantom, other cells were diluted by mixing them with $0.5 \%$ w/w gellan gum (P-8169; Sigma Chemicals Corp., St. Louis, MO, USA), which had been dissolved in distilled water (DW), and highly concentrated phosphate-buffered saline (PBS). The final concentrations were adjusted to $0.125 \% \mathrm{w} / \mathrm{w}$ gellan gum in PBS and $0.25 \%$ w/w gellan gum in PBS.

Cell destruction by sonication. Cells were treated 8 times for $9.9 \mathrm{sec}$ each at $0^{\circ} \mathrm{C}$ with 60 watts in a sonication device (Sonics and Materials, Inc., Newtown, CT, USA). Then, the cells were diluted by mixing them with $0.5 \% \mathrm{w} / \mathrm{w}$ gellan gum which had been dissolved in DW, and highly concentrated PBS, to yield a final concentration of $0.25 \% \mathrm{w} / \mathrm{w}$ gellan gum in PBS.

Alteration of salt concentration of the extracellular fluid. To alter the salt concentration of the extracellular fluid, the cells were mixed with $0.5 \% \mathrm{w} / \mathrm{w}$ gellan gum which had been dissolved in DW, and the mixture of cells and gellan gum was then dissolved in either low- or high-salt concentrated PBS. The final concentrations were adjusted to $0.25 \% \mathrm{w} / \mathrm{w}$ gellan gum in two different PBS solutions, one with a salt concentration of 0.5 times (low), and the other with a salt concentration of 1.5 times (high).

Other cells were mixed with PBS with a low and high salt concentration, thereby respectively yielding a low-salt concentrate suspension in 0.5 PBS and a high-salt suspension in 1.5 PBS. The cells were then spun down and used for encapsulation.

Observation of cell morphology after each treatment. After each treatment, the cells were stained with Hoechst 33342 and were observed by phase-contrast fluorescent microscopy. Images of 50 cells were analyzed using the Image-J image processing software (National Institutes of Health, Bethesda, MD, USA). The diameters of the nuclei and cells were measured with fluorescent Hoechst 33342 images and brightfield images, respectively, in order to calculate the nuclear and cellular volumes as $4 \pi r^{3} / 3$ (r, radius), and the nuclearcellular volume ratios.

Encapsulation of cells into a bio-phantom. We created biophantoms that encapsulated Jurkat-N1 cells (Fig. 1A). We initially created a well (Fig. 1A-c) with dimensions of $7 \mathrm{~mm}$ x $7 \mathrm{~mm} \times 30 \mathrm{~mm}$ in order to enclose the tumor cells (Fig. 1A-b) in the phantom case (Fig. 1A-a), which was $22 \mathrm{~mm}$ in diameter, and $54 \mathrm{~mm}$ in height (93-3825-3; Sansyo, Tokyo, Japan). The well was made of $0.25 \% \mathrm{w} / \mathrm{w}$ gellan gum that had been heated and dissolved in PBS. For experimental observation of the effects of changes in the salt concentration of the extracellular fluid, the wells were made of $0.25 \% \mathrm{w} / \mathrm{w}$ gellan gum heated and dissolved in PBS of low or high concentration, to respectively yield solutions with PBS salt concentrations of 0.5 or 1.5 .

The cells were placed into the well, after cellularity was quantified by an electric cell counter (Coulter Electronics, Ltd., Luton, UK). The well was then sealed with $0.25 \%$ w/w gellan gum.

\section{Preparation of bio-phantom containing animal tissue}

Tumor creation and extraction. Five-week-old skid mice were obtained at 6 weeks of age from the mouse colony at Okayama University. The mice were housed under pathogenfree conditions in the animal facilities at Okayama University, where sterilized food and water were provided ad libitum. The animal experiment protocols were approved by the Animal Care and Use Committees of Okayama University. The Jurkat-N1 cell suspension was transplanted into the mice under the back skin. The area of tumor cell transplantation was inspected once per week to check for possible tumor growth. In cases when a tumor was noted at 118 days post- 


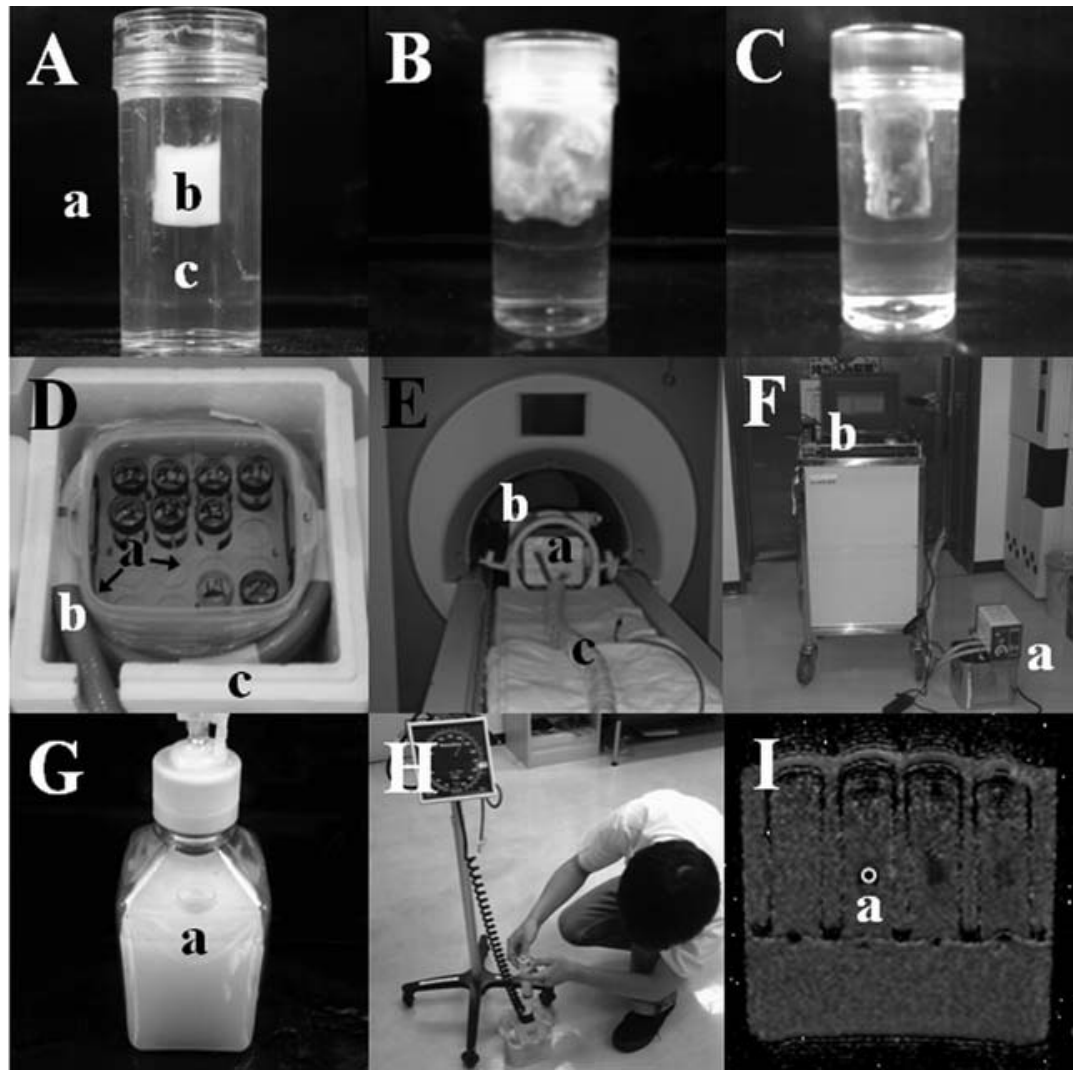

Figure 1. The phantom and methods used. (A) Bio-phantom that encapsulated the tumor cells. (a) Phantom case; (b) enclosed tumor cells; (c) well. (B) Biophantom, including tumor tissue. (C) Bio-phantom, including mouse liver. (D) Phantom case container. (a) Phantom case container filled with 0.9\% w/w sodium chloride solution and $0.03 \% \mathrm{w} / \mathrm{w} \mathrm{NaN}_{3}$; (b) tube around the container; (c) styrofoam box. (E) MR imaging of phantoms. (a) Styrofoam box, including the phantom case container; (b) head coil in the clinical MRI system (1.5 T Magnetom VISION); (c) tube connection between the container and the circulating temperature-regulated water bath. (F) Heating device for phantoms and a thermometer. (a) Circulating temperature-regulated water bath; (b) optical fiber thermometer used for temperature-monitoring in phantoms during MR imaging. (G) Pressurizing device. (a) Phantom case in carrageenan. (H) Pressurizing procedure carried out using pumped air and a pressure gauge. (I) ADC map. (a) Circular region of interest (ROI) at the center of cells in the phantom on the ADC map.

transplantation, the mouse was sacrificed, and the tumor and the liver were extracted.

Encapsulation of animal tissue into the bio-phantom. We first created a well that consisted of $0.25 \% \mathrm{w} / \mathrm{w}$ gellan gum heated and dissolved by PBS in order to enclose the animal tissue in the phantom case. The extracted mouse tumor and liver tissues were placed into the well (Fig. 1B and C), which was then sealed with $0.25 \%$ w/w gellan gum.

Preparation of control phantoms. The each following material was encapsulated in a phantom case in order to create control phantoms: DW, RPMI-1640, PBS, $0.125 \%$ w/w gellan gum diluted with PBS, and $0.25 \% \mathrm{w} / \mathrm{w}$ gellan gum diluted with PBS.

\section{Treatment of phantoms during MR imaging}

Heat treatment of phantoms. We developed a heating device that enabled us to apply direct heat to the phantoms during MR imaging, i.e., when placed in the MRI system. The container of the phantom case (Fig. 1D-a) was covered with a tube (Fig. 1D-b). Both the container and tube were enclosed in a styrofoam box (Fig. 1D-c and E-a). The tube (Fig. 1D-b and E-c) around the container was connected to a circulating temperature-regulated water bath (Fig. 1F-a; Thermo-mate BF-41, Yamato Scientific Co., Ltd., Tokyo, Japan). The phantoms were gradually heated to temperatures monitored within a range of $27-45^{\circ} \mathrm{C}$ during MR imaging (Fig. 1F).

For MR imaging under a constant temperature at $37^{\circ} \mathrm{C}$, the phantoms were heated by a temperature-regulated water bath. The phantom-case container (Fig. 1D-a) and other containers (Fig. 1G) were enclosed in a styrofoam box during MR imaging.

An optical fiber thermometer (Fig. 1F-b; Fluoroptic ${ }^{\text {TM }}$ Thermometer m600, Luxtron Co., Santa Clara, CA, USA) was used for temperature monitoring of the phantoms during MR imaging.

Phantom pressure treatment. We created a pressurizing device that enabled us to directly pressurize the phantoms in the MRI system during MR imaging. Carrageenan (314-7715750; Sigma Chemicals Corp.) was heated and melted with PBS, and was then mixed with $\mathrm{NaN}_{3}$ to yield a final concentration of $4 \% \mathrm{w} / \mathrm{w}$ carrageenan and $0.03 \% \mathrm{w} / \mathrm{w} \mathrm{NaN}$. Melted carrageenan was solidified in a 500-ml plastic container (Fig. 1G) to form the well that contained the phantom case (Fig. 1G-a). A pressure gauge was connected to the cap of the container via a three-way cock. Air was added to the 

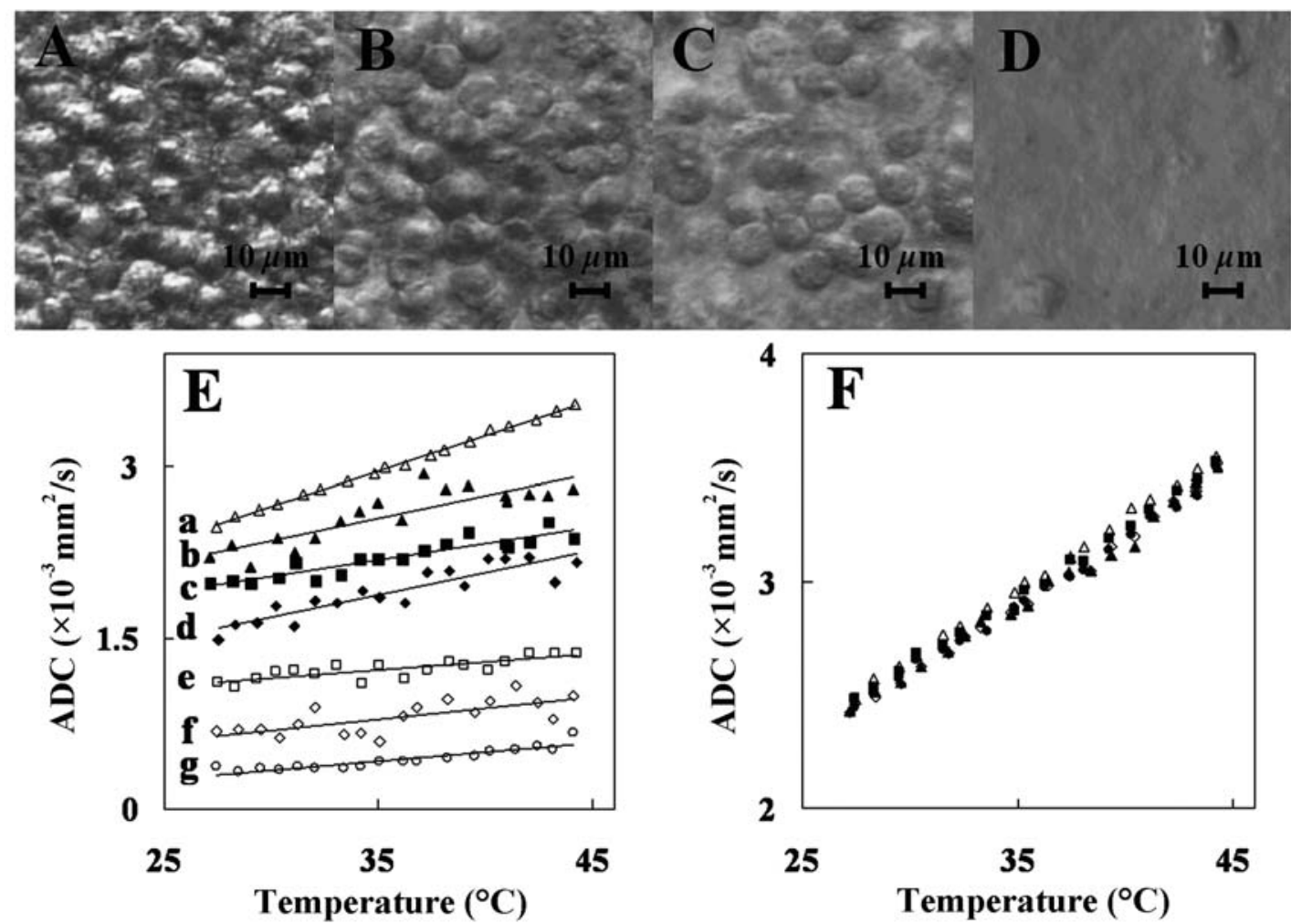

Figure 2. Microscopic images and ADC values of cells and tissues under different conditions. (A) The bright-field microscopic image of 5.73x $10^{8}$ cells $/ \mathrm{ml}$. (B) The bright-field microscopic image of $4.11 \times 10^{8}$ cells $/ \mathrm{ml}$. (C) The bright-field microscopic image of $1.89 \times 10^{8}$ cells $/ \mathrm{ml}$. (D) The bright-field microscopic image of $1.89 \times 10^{8}$ cells $/ \mathrm{ml}$ cells treated by sonication. (E) ADC values of phantoms, including cells and tissue and DW as a function of phantom temperatures. (a) DW; (b) $1.89 \times 10^{8}$ cells $/ \mathrm{ml}$ treated by sonication; (c) $1.89 \times 10^{8}$ cells $/ \mathrm{ml}$; (d) $4.11 \times 10^{8} \mathrm{cell} / \mathrm{s} / \mathrm{ml}$; (e) $5.73 \times 10^{8}$ cells $/ \mathrm{ml}$; (f) mouse liver; (g)

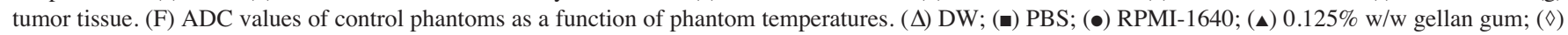
$0.25 \% \mathrm{w} / \mathrm{w}$ gellan gum.

container such that the phantom in the container could be pressurized at $300 \mathrm{mmHg}$ (Fig. 1H). The container was enclosed in a styrofoam box during MR imaging.

\section{MR imaging}

Diffusion-weighted MR imaging. In this study, a clinical 1.5-T MRI system (Magnetom Vision, Siemens, Erlangen, Germany) and head coil (Fig. 1E-b) were used for imaging. The scan parameters were as follows: TR, $4000 \mathrm{~ms}$; TE, $100 \mathrm{~ms}$; number of excitations, 2; matrix, $98 \times 128$; field of view, 210x210 mm; b value, 0, 500 and $1000 \mathrm{sec} / \mathrm{mm}^{2}$; and thickness, $3 \mathrm{~mm}$. The DWI images of three directions, phaseencoding, readout and slice-selective direction, were taken by using a multi-shot spin-echo echo-planar imaging (SE-EPI) sequence.

A maximum of 4 phantoms were used in each imaging session. Each image was obtained while the sample was exposed to increasing heat, i.e., $\sim 1^{\circ} \mathrm{C}$ intervals of increasing temperature from 27 to $45^{\circ} \mathrm{C}$ were applied to the phantoms.

Calculation of ADC value. The signal intensities in each pixel of the DWI images in each direction were plotted on the vertical axis of the graph as a function of the b values on the lateral axis. The slope of the regression line was obtained by the least-squares method and was defined as the ADC value in each direction. ADC values obtained from three directions were averaged for each pixel. The averaged ADC values were plotted on each pixel as an ADC map. We placed circular regions of interest (ROIs, Fig. 1I-a) at the center of cells and tumors in phantoms on ADC maps, and we selected and averaged the ADC values in each ROI using Image-J image processing software.

\section{Results}

Change in ADC values of cells and tissues under different conditions. We changed the cellularity as follows: $5.73 \times 10^{8}$ cells $/ \mathrm{ml}$ (cell pellet, Fig. 2A), $4.11 \times 10^{8}$ cells $/ \mathrm{ml}$ (cell pellet mixed in $0.125 \%$ w/w gellan gum, Fig. $2 \mathrm{~B}$ ) and $1.89 \times 10^{8}$ cells/ $\mathrm{ml}$ (cell pellet mixed in $0.25 \% \mathrm{w} / \mathrm{w}$ gellan gum, Fig. 2C), using gellan gum. Microscopic observations (Fig. 2A-C) indicated that the extracellular space increased as cellularity decreased. The ADC values decreased in the following order: $1.89 \times 10^{8}$ cells $/ \mathrm{ml}$ cells (Fig. $2 \mathrm{E}-\mathrm{c}$ ), $4.11 \times 10^{8}$ cells $/ \mathrm{ml}$ cells (Fig. 2E-d), 5.73× $10^{8}$ cells $/ \mathrm{ml}$ cells (Fig. 2E-e), mouse liver (Fig. 2E-f), and tumor tissue (Fig. 2E-g), as shown in Fig. 2E.

The ADC values of control phantoms (RPMI-1640, PBS, $0.125 \% \mathrm{w} / \mathrm{w}$ gellan gum diluted with PBS and $0.25 \% \mathrm{w} / \mathrm{w}$ gellan gum diluted with PBS) were virtually identical to the ADC value of a control phantom (DW) (Fig. 2F).

Changes in ADC values of cells destroyed by sonication. As sonication destroys cellular membranes, we were unable to recognize the cellular morphology of the sonicated $1.89 \times 10^{8}$ cells $/ \mathrm{ml}$ sample mixed in $0.25 \% \mathrm{w} / \mathrm{w}$ gellan gum 

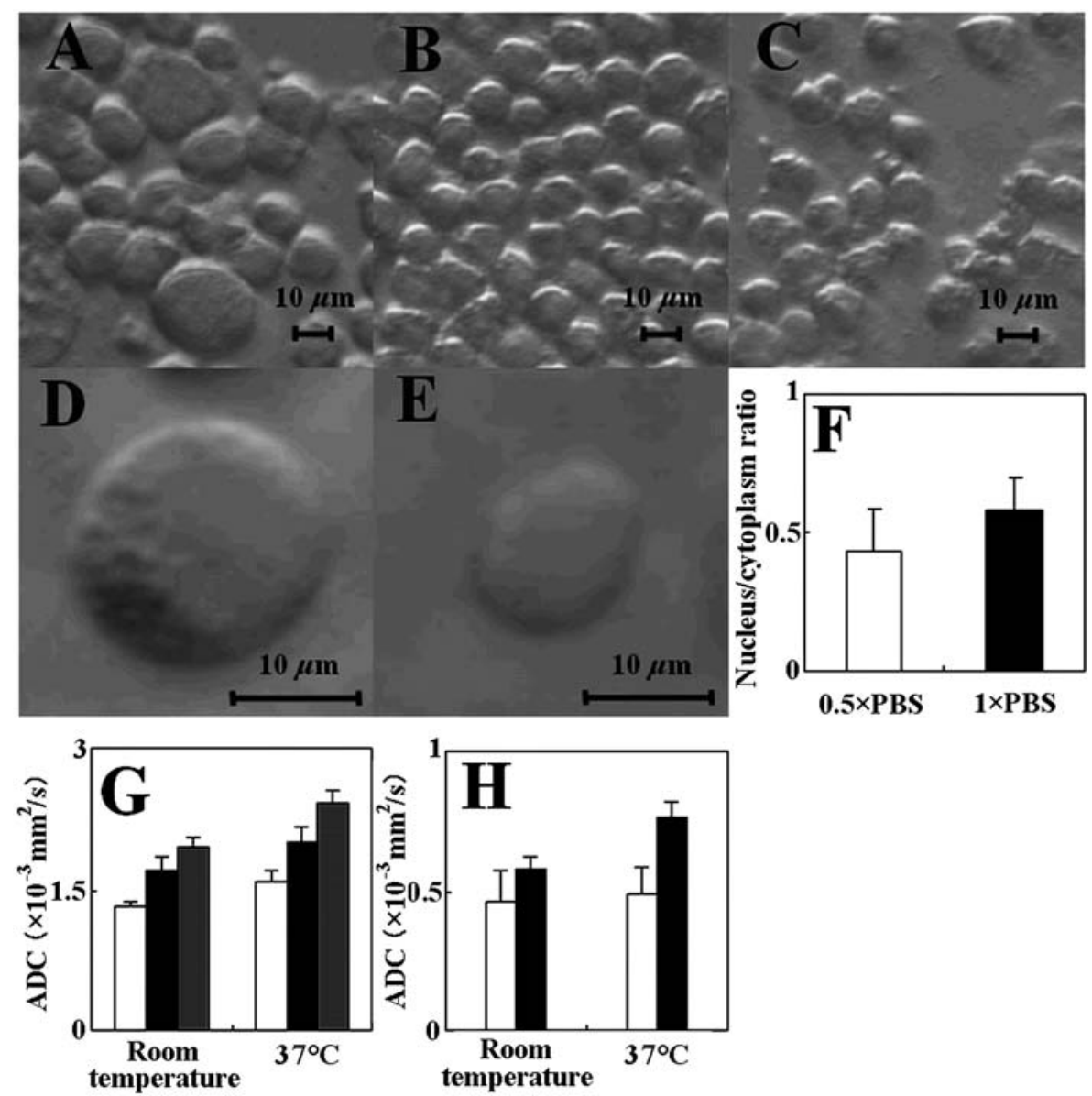

Figure 3. Change in ADC values and cellular morphology by salt concentration. (A) Bright-field microscopic image of cells in $0.25 \%$ w/w gellan gum and in PBS with a low (0.5) salt concentration. (B) Bright-field microscopic image of cells in $0.25 \%$ w/w gellan gum and PBS. (C) Bright-field microscopic image of cells in $0.25 \%$ w/w gellan gum and in PBS with a high (1.5) salt concentration. (D) Fluorescent images (Hoechst 33342 ) of cells in 0.25\% w/w gellan gum and in PBS with a low (0.5) salt concentration. (E) Fluorescent images (Hoechst 33342) of cells in $0.25 \%$ w/w gellan gum and PBS. (F) The nucleus/ cytoplasm ratio of cells in $0.25 \% \mathrm{w} / \mathrm{w}$ gellan gum and in PBS with a low salt concentration ( $0.5 \mathrm{X}$ PBS, white column) and cells in $0.25 \%$ w/w gellan gum and PBS (1X PBS, black column). The error bars represent one standard deviation. (G) The ADC values at room temperature and $37^{\circ} \mathrm{C}$ by salt concentration Cells in $0.25 \% \mathrm{w} / \mathrm{w}$ gellan gum and in PBS with a low (0.5) salt concentration (white column). Cells in $0.25 \%$ w/w gellan gum and PBS (black column). Cells in $0.25 \% \mathrm{w} / \mathrm{w}$ gellan gum and in PBS with a high (1.5) salt concentration (gray column). The error bars represent one standard deviation. (H) The ADC values of cell pellets in PBS with a low (0.5) salt concentration (white column) and cell pellets in PBS (black column), both at room temperature and at $37^{\circ} \mathrm{C}$. The error bars represent one standard deviation.

under microscopic observation (Fig. 2D). The ADC value of the cells increased after sonication (Fig. 2E-b, E-c).

Change in ADC values by temperature. The ADC value of each of the bio-phantoms (containing cells or tissue) and control phantoms increased with temperature increases, as shown in Fig. 2E and F. The ADC value-increasing rates per $1{ }^{\circ} \mathrm{C}$ were heterogeneous and varied from $0.014 \times 10^{-3} \mathrm{~mm}^{2}$ / $\mathrm{sec} /{ }^{\circ} \mathrm{C}$ to $0.062 \times 10^{-3} \mathrm{~mm}^{2} / \mathrm{sec} /{ }^{\circ} \mathrm{C}$.

Changes in ADC values and cellular morphology by salt concentration. The $5.73 \times 10^{8}$ cells $/ \mathrm{ml}$ sample in $0.25 \% \mathrm{w} / \mathrm{w}$ gellan gum and in PBS with a low (0.5) salt concentration (Fig. 3A) showed edema, swelling and increases in size over that of cells in $0.25 \% \mathrm{w} / \mathrm{w}$ gellan gum and PBS (Fig. 3B). The cells in $0.25 \% \mathrm{w} / \mathrm{w}$ gellan gum and in PBS with a high (1.5) salt concentration (Fig. 3C) shrank to a smaller size than that of cells in $0.25 \%$ w/w gellan gum and PBS (Fig. 3B).

Nuclear staining with Hoechst 33342 demonstrated that the cytoplasm of cells in $0.25 \% \mathrm{w} / \mathrm{w}$ gellan gum and in PBS with a low (0.5) salt concentration increased more markedly than did the nucleus of the same cells (Fig. 3D and E). The nucleus/cytoplasm ratio of cells in $0.25 \% \mathrm{w} / \mathrm{w}$ gellan gum and in PBS with a low (0.5) salt concentration was $0.43 \pm 0.16$, and thus was smaller than that of cells in $0.25 \% \mathrm{w} / \mathrm{w}$ gellan gum and PBS, i.e., $0.58 \pm 0.12$ (Fig. 3F).

The ADC values of cells in $0.25 \% \mathrm{w} / \mathrm{w}$ gellan gum and in PBS with a low (0.5) salt concentration at room temperature and at $37^{\circ} \mathrm{C}$ were lower than the ADC values of cells in $0.25 \% \mathrm{w} / \mathrm{w}$ gellan gum and PBS. The ADC values of cells in $0.25 \% \mathrm{w} / \mathrm{w}$ gellan gum and in PBS with a high (1.5) salt concentration at room temperature and at $37^{\circ} \mathrm{C}$ were higher than the ADC values of cells in $0.25 \% \mathrm{w} / \mathrm{w}$ gellan gum and PBS (Fig. 3G).

Moreover, the ADC values of cell pellets in PBS with a low (0.5) salt concentration at room temperature and at $37^{\circ} \mathrm{C}$ were lower than those of cell pellets in PBS (Fig. 3H).

Changes in ADC values by pressure. A pressure of $300 \mathrm{mmHg}$ did not alter $\mathrm{ADC}$ values at $37^{\circ} \mathrm{C}$ of samples containing the 


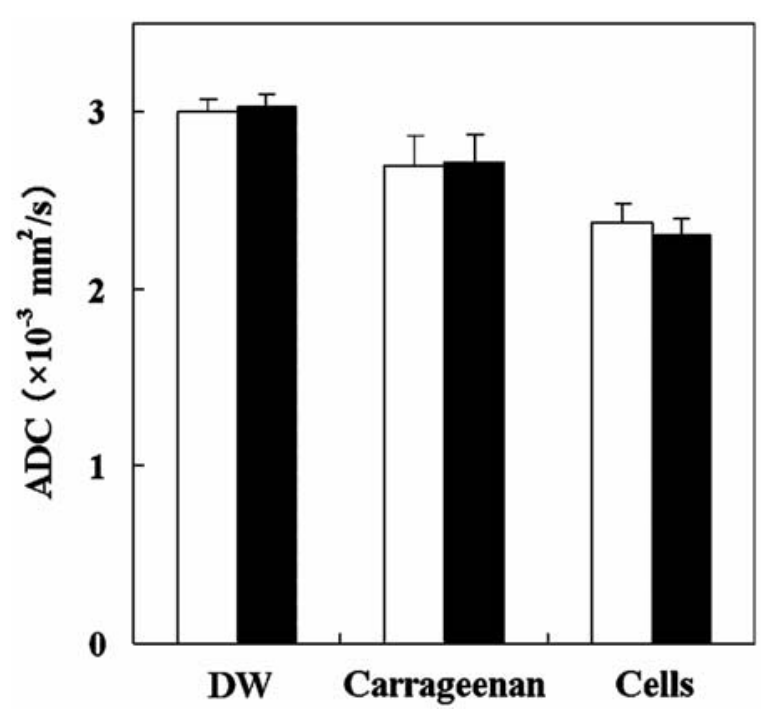

Figure 4. Change in $\mathrm{ADC}$ values by pressure. No alteration of $\mathrm{ADC}$ values was observed under $300 \mathrm{mmHg}$ pressure (black column) at $37^{\circ} \mathrm{C}$ in the case of DW, $4 \% \mathrm{w} / \mathrm{w}$ carrageenan, and $6.35 \times 10^{7}$ cells $/ \mathrm{ml}$, compared with the ADC values of corresponding samples under zero pressure $(0 \mathrm{mmHg}$; white column). The error bars indicate one standard deviation.

following: DW, $4 \% \mathrm{w} / \mathrm{w}$ carrageenan, and $6.35 \times 10^{7}$ cells $/ \mathrm{ml}$, in contrast to with the altered ADC values of corresponding samples under a pressure of $0 \mathrm{mmHg}$ (Fig. 4).

\section{Discussion}

It is well known that ADC values are lower in tumorous tissue than in the surrounding normal tissue. However, the mechanism driving this difference has remained obscure. In general, factors that affect the diffusion of water molecules [e.g., differences in cellularity $(6,12)$, cellular necrosis and edema (11), temperature (10), viscosity (10), etc.] have been reported to be associated with changes in ADC values. In the present series, we used uniform cellular bio-phantoms to investigate alterations in the ADC values of cells according to cellularity, cellular edema caused by low salt concentration, cell sonication (which destroys the cell membrane and enlarges the extracellular space), and pressurization [which may increase viscosity (13)]. The ADC values of cells increased as the temperature increased and as plasma membranes were destroyed by sonication. Increases in cellularity and decreases in salt concentration reduced the ADC values of the cells. Pressurization was not found to alter the ADC values of the cells examined. These results indicate that increases in cellularity and cellular edema are related not only to increases in intracellular space, but also to the narrowness of the extracellular space, which in turn reduces ADC values. It is also well known that ADC values are related to viscosity (10). Moreover, viscosity has also been related to pressure (13). We investigated the relationship between pressure and ADC values using bio-phantoms in order to examine whether or not the known decrease in the ADC values of tumors is related to any increases in intra-tumoral pressure. Our results did not suggest that increases in intratumoral pressure are causing the observed decrease in the ADC values of tumors.

MR images of cells have been acquired and presented in subsequent reports. There are several methods of conducting MR imaging of cells, including the use of cell pellets (14), gelatinous material including cells (15-19), and particular instruments for cell culture $(9,20)$. Only two reports $(9,20)$ have investigated the ADC values of cells using a particular cell culture device referred to as a 'Hollow fiber' device together with an experimental MRI system.

This is the first report of the ADC values of cells using cell pellets, gelatinous material containing cells, and a clinical MRI system. Several previously applied methods have
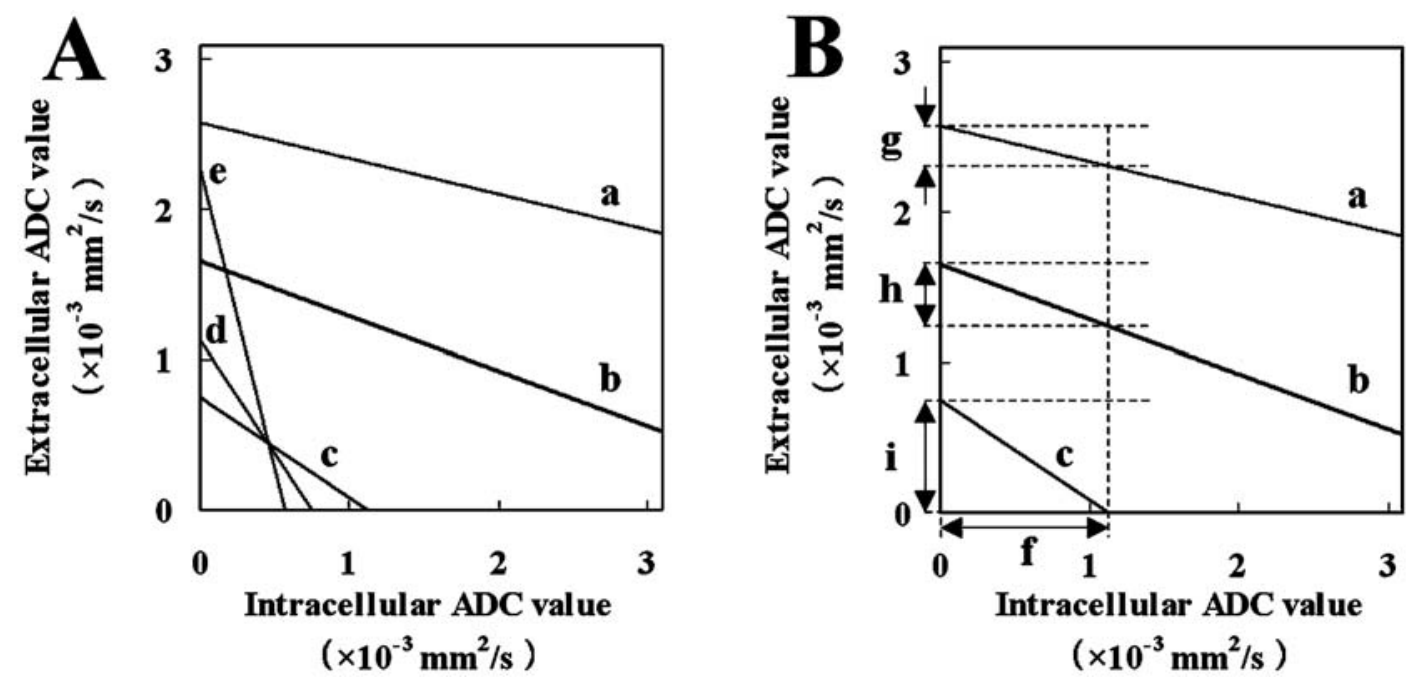

Figure 5. The relationship between intracellular and extracellular ADC values. (A) The relationship between intracellular and extracellular ADC values of $4.11 \times 10^{8}$ cells $/ \mathrm{ml} \mathrm{(a),} 5.73 \times 10^{8}$ cells $/ \mathrm{ml}(\mathrm{b})$, and tumorous tissue (c-e), assuming that the cell fractions in the tumorous tissue were 0.4 (c), 0.6 (d) and 0.8 (e). (B) The relationship between intracellular and extracellular ADC values when the cell fraction in the tumorous tissue was 0.4. (f) Range of intracellular ADC values; $(\mathrm{g})$ range of extracellular ADC values of $4.11 \times 10^{8}$ cells $/ \mathrm{ml}$; (h) range of extracellular ADC values of $5.73 \times 10^{8}$ cells $/ \mathrm{ml}$; (i) the range of extracellular $\mathrm{ADC}$ values of tumorous tissue in which the cell fraction was 0.4 . 
Table I. ADC values of phantoms and the cell fractions used for calculations.

\begin{tabular}{lcccc}
\hline & $\begin{array}{c}\text { ADC } \\
\left(\times 10^{-3} \mathrm{~mm}^{2} / \mathrm{sec}\right)\end{array}$ & $\begin{array}{c}\text { Cellularity } \\
(\text { cells/ml })\end{array}$ & $\begin{array}{c}\text { Volume of } \\
\text { one cell }(\mathrm{ml})\end{array}$ & Cell fractions \\
\hline Tumor tissue & 0.45 & - & $4.66 \times 10^{-10}$ & 0.267 \\
$5.73 \times 10^{8}$ cells $/ \mathrm{ml}$ & 2.08 & $5.73 \times 10^{8}$ & $4.66 \times 10^{-10}$ & 0.191 \\
$4.11 \times 10^{8}$ cells $/ \mathrm{ml}$ & 2.27 & $4.11 \times 10^{8}$ & $4.66 \times 10^{-10}$ & \\
\hline
\end{tabular}

Table II. Range of intracellular and extracellular ADC values for each cell fraction.

\begin{tabular}{lcccc}
\hline & & \multicolumn{3}{c}{ Extracellular ADC value $\left(\mathrm{x} 10^{-3} \mathrm{~mm}^{2} / \mathrm{sec}\right)$} \\
\cline { 3 - 5 } $\begin{array}{l}\text { Cell } \\
\text { fraction }\end{array}$ & $\begin{array}{c}\text { Intracellular ADC value } \\
\left(\mathrm{x} 10^{-3} \mathrm{~mm}^{2} / \mathrm{sec}\right)\end{array}$ & $\begin{array}{c}\text { Tumor } \\
\text { tissue }\end{array}$ & $\begin{array}{c}5.73 \times 10^{8} \\
\text { cells } / \mathrm{ml}\end{array}$ & $\begin{array}{c}4.11 \times 10^{8} \\
\mathrm{cells} / \mathrm{ml}\end{array}$ \\
\hline 0.8 & $0.00-0.56$ & $0.00-2.25$ & $1.45-1.65$ & $2.44-2.57$ \\
0.6 & $0.00-0.75$ & $0.00-1.13$ & $1.38-1.65$ & $2.39-2.57$ \\
0.4 & $0.00-1.12$ & $0.00-0.75$ & $1.24-1.65$ & $2.31-2.57$ \\
\hline
\end{tabular}

involved gelatin $(17,18), 1-2 \%$ agarose $(15,16)$ or low-melting agarose (19) for the MR imaging of cells. With these previously reported methods, there remains the possibility that cells could be affected by heat, as gelatinous materials melt when exposed to heat at temperatures of $40^{\circ} \mathrm{C}$ (19) or $60^{\circ} \mathrm{C}$ (18) before the step of embedding cells. Here, we developed a novel method of enclosing cells into biophantoms using gellan gum at room temperature, which obviated the need to apply heat. Gellan gum is a linear, anionic heteropolysaccharide produced by the microorganism Sphingomonas elodea $(21,22)$. Gellan gum is harmless, and is used in the food industry, primarily as a gelling agent. Gellan gum has a molecular structure based on a tetrasaccharide repeating unit composed of (1-3)- $\beta$-D-glucose, (1-4)- $\beta$-Dglucuronic acid, (1-4)- $\beta$-D-glucose, and (1-4)- $\beta$-L-rhamnose as the backbone with acyl substituents of L-glycerate and acetate at the C-2 and C-6 (approximately 50\%) positions of the (1-3)-linked D-glucose, respectively (23). Gellan gum turns into a gel by a bridge bond to L-glyceryl radical (24). The heated gellan gum solution forms a gel not only with a reduction in temperature, but also in the presence of a metal ion. We made use of this characteristic of gellan gum, and solidified the cooled gellan gum solution by the addition of salt to encapsulate living cells into bio-phantoms at room temperature. This method enabled the MR imaging of cells under physiological conditions, which provides an advantage over previously reported conventional methods.

Diffusion-weighted MRI is in common clinical use, and has been made available for whole-body screening for tumors (1). The exact mechanism by which ADC values decrease in tumors has remained unclear to date. Sugahara et al (6) and Lyng et al (12) reported that ADC values decreased as cellularity increased. Schoeniger et al (8) and Sehy et al (10) investigated the ADC values of an individual cell, and reported that diffusion in the cell cytoplasm was more inhibited than that in the nucleus. These results appear to support the notion that intracellular ADC values are crucial for determining the ADC values of tumors. On the other hand, Koh and Collins (11) reported that ADC values increase with increases in the extracellular space due to the destruction of cellular membranes following anticancer drug treatment. Thus, the extracellular ADC value appears to play an important role in determining the ADC value of a tumor.

We also considered the relative degrees to which the intracellular and extracellular space respectively contribute to the determination of the ADC values of bio-phantoms. Therefore, we considered the experimental ADC values of the bio-phantoms created for this series. We assumed that the ADC value in a boxel would be determined by the ratio of the ADC values of the intracellular space and the extracellular space. Thus, the ADC value in a boxel was calculated as follows:

$$
\mathrm{ADC} \text { value }=[\mathrm{a} \times \mathrm{b}+\mathrm{c} \times(1-\mathrm{b})],[1]
$$

where (a) is the intracellular ADC value, (c) is the extracellular ADC value, and (b) is the fraction of cells.

We were able to determine the relationship between the intracellular and extracellular ADC values (plotted in Fig. 5), as we had determined ADC values of the phantoms and the fractions of cells, which were substituted into equation [1] in this experiment. The ADC values of the phantoms and the cell fractions used for the calculations are summarized in Table I. The fraction of cells was determined by multiplying cellularity by a mean cellular volume of 50 cells. Each cellular volume was calculated from the radius (r) of a cell, defined as $4 \pi r^{3} / 3$. As regards calculations for tumor tissues, the exact fraction of cells remained unclear, but was assumed to be greater than 0.267 (i.e., the fraction of the cell pellet) and less than 0.74 [i.e., the maximum filling fraction of spheres in a cube as calculated using the Kepler conjecture (25)]. We 
plotted the relationship between the intracellular and extracellular ADC values of the tumor tissue based on the assumption that the cells fractions in the tumorous tissue were $0.4,0.6$, and 0.8 (Fig. $5 \mathrm{~A}$ ). Fig. $5 \mathrm{~A}$ shows that the extracellular $\mathrm{ADC}$ values in the phantoms were lower than the ADC value of DW, i.e., $3.10 \times 10^{-3} \mathrm{~mm}^{2} / \mathrm{sec}$. This finding indicates that not only the intracellular ADC values, but also the extracellular ADC values play an important role in determining the ADC values of the phantoms.

We also considered the range of intracellular and extracellular ADC values based on the assumption that the intracellular ADC values of Jurkat-N1 cells and tumors would be identical among phantoms, as shown in Fig. 5B. For example, in the case of a 0.4 cell-fraction value, the range of intracellular ADC values was between $0.00 \times 10^{-3} \mathrm{~mm}^{2} / \mathrm{sec}$ and $1.12 \times 10^{-3} \mathrm{~mm}^{2} / \mathrm{sec}$, the range of extracellular ADC values of $5.73 \times 10^{8}$ cells $/ \mathrm{ml}$ was between $1.24 \times 10^{-3} \mathrm{~mm}^{2} / \mathrm{sec}$ and $1.65 \times 10^{-3} \mathrm{~mm}^{2} / \mathrm{sec}$, the range of extracellular ADC values of $4.11 \times 10^{8}$ cells $/ \mathrm{ml}$ was between $2.31 \times 10^{-3} \mathrm{~mm}^{2} / \mathrm{sec}$ and $2.57 \times 10^{-3} \mathrm{~mm}^{2} / \mathrm{sec}$, and the range of the extracellular ADC value of the tumorous tissue was between $0.00 \times 10^{-3} \mathrm{~mm}^{2} / \mathrm{sec}$ and $0.75 \times 10^{-3} \mathrm{~mm}^{2} / \mathrm{sec}$ (Fig. 5B). In Table II, we have summarized these ranges in each case examined (i.e., 0.4, 0.6 and 0.8 as the cell fraction).

No reports to date have provided the precise ADC values of the intracellular and extracellular space in tumorous tissue. This is the first study to have investigated the degree of contribution of the intracellular and extracellular space on the determination of ADC values using cultured cells and a clinical MRI system. Ultimately, our findings suggest that not only intracellular ADC values, but also extracellular ADC values, play an important role in the determination of the ADC values of bio-phantoms and tumorous tissues. Increases in cellularity and cellular edema may be related not only to increases in intracellular space, but also to the narrowness of the extracellular space, which in turn may reduce ADC values. New bio-phantoms created for basic MRI studies could serve as tools for elucidating the precise mechanisms involved in DWI for clinical use.

\section{Acknowledgements}

The authors would like to thank their collaborators in the Central Division of Radiology at Okayama University Hospital for their support of this study.

\section{References}

1. Sehy JV, Zhao L, Xu J, Rayala HJ, Ackerman JJ and Neil JJ: Effects of physiologic challenge on the ADC of intracellular water in the Xenopus oocyte. Magn Reson Med 52: 239-247, 2004.

2. Moffat BA, Hall DE, Stojanovska J, et al: Diffusion imaging for evaluation of tumor therapies in preclinical animal models. Magn Reson Mat Phys Biol Med 17: 249-259, 2004.

3. Moffat BA, Chenevert TL, Lawrence TS, et al: Functional diffusion map: a non-invasive MRI biomarker for early stratification of clinical brain tumor response. Proc Natl Acad Sci USA 102: 5524-5529, 2005.
4. Jordan BF, Runquist M, Raghunand N, et al: Dynamic contrastenhanced and diffusion MRI show rapid and dramatic changes in tumor microenvironment in response to inhibition of HIF-1A using PX-478. Neoplasia 7: 475-485, 2005.

5. Pui $\mathrm{MH}$ and Wang Y: Diffusion and magnetization transfer MRI of brain infarct, infection, and tumor in children. Clin Imaging 29: 162-171, 2005.

6. Sugahara T, Korogi Y, Kochi M, et al: Usefulness of diffusionweighted MRI with echo-planar technique in the evaluation of cellularity in gliomas. J Magn Reson Imaging 9: 53-60, 1999.

7. Mürtz P, Krautmacher C, Träber F, Gieseke J, Schild HH and Willinek WA: Diffusion-weighted whole-body MR imaging with background body signal suppression: a feasibility study at 3.0 Tesla. Eur Radiol 17: 3031-3037, 2007.

8. Schoeniger JS, Aiken N, Hsu E and Blackband SJ: Relaxationtime and diffusion NMR microscopy of single neurons. J Magn Reson 103: 261-273, 1993.

9. Galons JP, Lope-Piedrafita S, Divijak JL, Corum C, Gillies RJ and Trouard TP: Uncovering of intracellular water in cultured cells. Magn Reson Med 54: 79-86, 2005.

10. Sehy JV, Ackerman JJ and Neil JJ: Apparent diffusion of water, ions and small molecules in the Xenopus oocyte is consistent with brownian displacement. Magn Reson Med 48: 42-51, 2002.

11. Koh DM and Collins DJ: Diffusion-weighted MRI in the body: applications and challenges in oncology. Am J Roentgenol 188: 1622-1635, 2007.

12. Lyng H, Haraldseth $\mathrm{O}$ and Rofstad EK: Measurement of cell density and necrotic fraction in human melanoma xenografts by diffusion weighted magnetic resonance imaging. Magn Reson Med 43: 828-836. 2000.

13. Lauffer MA: Motion in viscous liquids: simplified derivations of the Stokes and Einstein equations. J Chem Educ 58: 250-256, 1981 .

14. Kang HW, Josephson L, Petrovsky A, Weissleder R and Bogdanov A: Magnetic resonance imaging of inducible Eselectin expression in human endothelial cell culture. Bioconjugate Chem 13: 122-127, 2002.

15. Weissleder R, Simonova M, Bogdanova A, Bredow S, Enochs WS and Bogdanov A Jr: MR imaging and scintigraphy of gene expression through melanin induction. Radiology 204: 425-429, 1997.

16. Schmalbrock P, Hines JV, Lee SM, Ammar GM and Kwok EW: T1 measurements in cell cultures: a new tool for characterizing contrast agents at 1.5T. J Magn Reson Imaging 14: 636-648, 2001.

17. Fleige G, Noltey C, Synowitzy M, Seeberger F, Kettenmann H and Zimmery $\mathrm{C}$ : Magnetic labeling of activated microglia in experimental gliomas. Neoplasia 3: 489-499, 2001.

18. Frank JA, Miller BR, Arbab AS, et al: Clinically applicable labeling of mammalian and stem cells by combining superparamagnetic iron oxides and transfection agents. Radiology 228: 480-487, 2003.

19. Billotey C, Wilhelm C, Devaud M, Bacri JC, Bittoun J and Gazeau F: Cell internalization of anionic maghemite nanoparticles: quantitative effect on magnetic resonance imaging. Magn Reson Med 49: 646-654, 2003.

20. Planchamp C, Ivancevic MK, Pastor CM, et al: Hollow fiber bioreactor: new development for the study of contrast agent transport into hepatocytes by magnetic resonance imaging. Biotechnol Bioeng 85: 656-665. 2004.

21. Jansson PE, Lindberg B and Sandford PA: Structural studies of gellan gum, an extracellular polysaccharide elaborated by Pseudomonas elodea. Carbohydr Res 124: 135-139, 1983.

22. O'Neill MA, Selvendran RR and Morris VJ: Structure of the acidic extracellular gelling polysaccharide produced by Pseudomonas elodea. Carbohydr Res 124: 123-133, 1983.

23. Kuo MS, Mort AJ and Dell A: Identification and location of L-glycerate, an unusual acyl substituent in gellan gum. Carbohydr Res 156: 173-187, 1986.

24. Chandrasekaran R, Radha A and Thailambal VG: Roles of potassium ions, acetyl and L-glyceryl groups in native gellan double helix: an X-ray study. Carbohydr Res 224: 1-17, 1992.

25. Hales TC: A proof of the Kepler conjecture. Ann Math 162: 1065-1185, 2005. 